\title{
Reloading the heart: A new animal model of left ventricular assist device removal
}

\author{
Tomohiro Mizuno, MD, Richard D. Weisel, MD, and Ren-Ke Li, MD, PhD
}

From the Division of Cardiovascular Surgery, Department of Surgery, Toronto General Research Institute, Toronto General Hospital, University of Toronto, Toronto, Ontario, Canada.

Ren-Ke Li is a Career Investigator of the Heart and Stroke Foundation of Canada. The study was supported by the CIHR (MOP62698) and HSFO (T5206) to R.K.L.

Received for publication April 21, 2004; revisions received Sept 20, 2004; accepted for publication Oct 1, 2004.

Address for reprints: Ren-Ke Li, MD, PhD, Toronto General Hospital, NU 1-115A, 200 Elizabeth St, Toronto, Ontario M5 2C4, Canada (E-mail: renkeli@uhnres.utoronto. ca)

J Thorac Cardiovasc Surg 2005;130:99-106

$0022-5223 / \$ 30.00$

Copyright (c) 2005 by The American Association for Thoracic Surgery

doi:10.1016/j.jtcvs.2004.10.002
Objectives: Left ventricular assist devices are proposed as a bridge to recovery, but recurrent ventricular deterioration has limited this approach. We describe a new animal model that simulates the effects of left ventricular assist device unloading and then reloading after device removal. The model might facilitate the evaluation of interventions intended to prevent recurrent ventricular dysfunction.

Methods: The hearts and lungs of Lewis rats were removed and transplanted into the abdomen of recipient rats by anastomosing the donor's ascending aorta to the recipient's abdominal aorta. The transplanted hearts were maintained unloaded for 2 weeks in 49 animals. Eighteen transplanted hearts were removed after 2 weeks of unloading. In 17 animals the donor's right pulmonary artery was anastomosed to the recipient's abdominal aorta to reload the heart for an additional 2 weeks. In 14 animals the hearts were maintained unloaded for 4 weeks (an additional 2 weeks). The unloaded and reloaded hearts were compared with normal rat hearts $(n=18)$.

Results: In the unloaded hearts the left ventricular end-diastolic pressures remained low. The left ventricular systolic pressures were lower than the aortic pressures. The left ventricular weights $(\mathrm{n}=8)$ and volumes $(\mathrm{n}=4)$ remained significantly lower $(P<.01)$ than in the normal hearts. Two weeks after reloading, the left ventricular end-diastolic pressure $(\mathrm{n}=8)$ increased $(P<.01)$, and the ventricle ejected. The left ventricular systolic pressures exceeded the aortic pressures. The left ventricular weights and volumes increased $(P<.01)$ and approached those of normal hearts. Matrix metalloproteinase 9 ( $\mathrm{n}=6$ /group) levels decreased in the unloaded state $(P=.02)$ and increased back to normal values after reloading.

Conclusions: This surgical model simulated left ventricular assist device unloading of the left ventricle. The second operation reloaded the left ventricle, which then enlarged. This model will permit the evaluation of adjunctive interventions, such as cell transplantation, intended to facilitate successful left ventricular assist device removal and prevent recurrent dilatation.

$\mathrm{L}$ eft ventricular assist devices (LVADs) are an effective treatment for patients with severely decompensated heart failure. As a bridge to transplantation, LVAD treatment permits recovery from heart failure and improves quality of life. ${ }^{1,2}$ LVAD support is accompanied by marked hemodynamic, neurohumoral, physiologic, cellular, and molecular changes of myocardial recovery. ${ }^{3-9}$ However, the use of an LVAD as a bridge to recovery remains controversial. ${ }^{10,11}$ Hetzer and colleagues $^{12}$ reported that 13 of 23 patients were successfully weaned from LVADs. Six of them remained free of subsequent cardiac failure after removal of the LVAD, but 7 patients had recurrent cardiac failure. Mancini and associates ${ }^{13}$ were unable to reproduce Dr Hetzer's experience. This group found that recurrent cardiac dilatation and worsening heart failure developed after LVAD removal. ${ }^{14}$ Although some patients have been successfully weaned from LVAD support, the process is unpredictable, and adjunctive therapies might be required to permit successful LVAD removal. ${ }^{15}$ 
(A) Unloading the heart

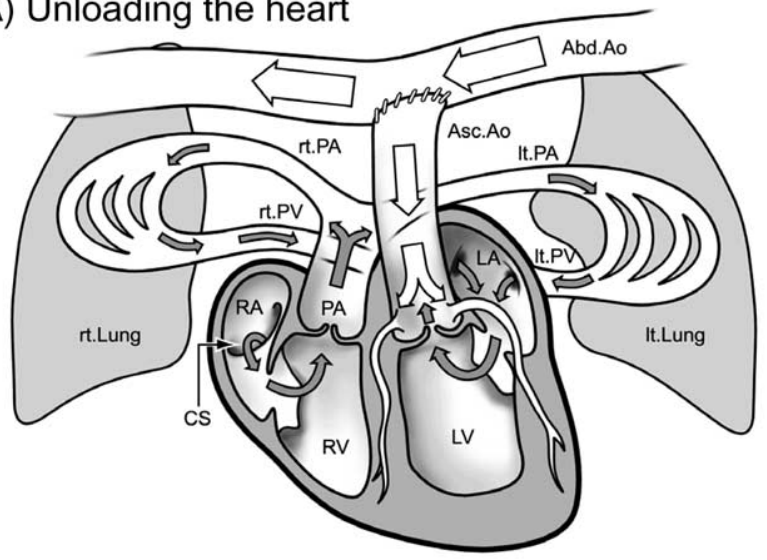

(B) Reloading the heart

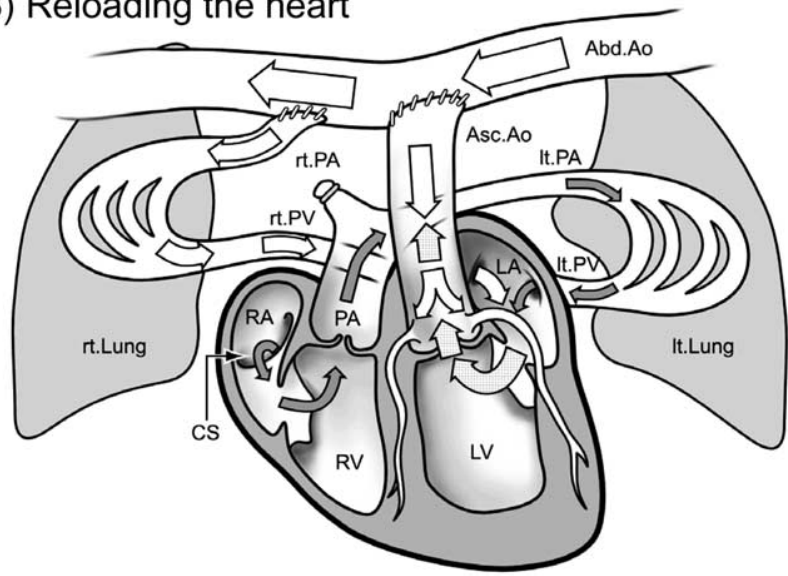

Figure 1. Heterotopic heart transplantation. A, Unloading the heart. The heart and lungs are transplanted into the abdomen of the recipient. The ascending aorta of the donor is anastomosed to the abdominal aorta of the recipient. B, Reloading the heart. The right $P A$ is anastomosed to the distal abdominal aorta of the recipient. The gray arrows indicate coronary flow, the white arrows indicate the blood flow from the abdominal aorta, and the light gray dotted arrows indicate the mixed blood. Asc.Ao, Ascending aorta; Abd.Ao, abdominal aorta; $P V$, Pulmonary vein; $R A$, right atrium; $L A$, left atrium; $R V$, right ventricle; $L V$, left ventricle; CS, coronary sinus; $r t$, right; It, left.

Cell transplantation prevented or delayed cardiac dilatation and dysfunction in models of progressive cardiomyopathy. ${ }^{16,17}$ Cell transplantation during LVAD therapy might prevent recurrent cardiac deterioration after LVAD removal. The potential benefits of cell transplantation or any other therapy to prevent recurrent ventricular dysfunction after LVAD removal have not been evaluated either in patients or in animal models. Therefore, we developed an animal model to simulate LVAD unloading followed by a period of reloading to simulate LVAD removal. The rat heterotopic heart transplant model was first reported in the 1960s. ${ }^{18,19}$ In the first model the hearts were unloaded, and therefore the model did not reflect the clinical situation. The surgical approaches were modified in the 1990s to permit cardiac loading. ${ }^{20-24}$ We further modified the surgical approaches to permit the heterotopic heart to be unloaded and then reloaded to simulate LVAD removal. This model will help to determine whether adjunctive therapy, such as cell transplantation, will prevent or delay recurrent cardiac failure after LVAD removal.

\section{Methods}

All experimental procedures were approved by the Animal Care Committee of the University Health Network. The studies were performed according to the guidelines in the "Guide to the Care and Use of Experimental Animals" (National Institutes of Health publication no. 85-23, revised 1985). Male Lewis inbred rats weighting 290 to 320 g (Charles River Canada Inc, Quebec, Canada) were used as donors, and those weighting 290 to $350 \mathrm{~g}$ were used as recipients.

\section{Outline of the Surgical Model}

The heart and lungs of the donor rat were transplanted heterotopically into the abdomen of the recipient rat. The ascending aorta of the donor heart was anastomosed to the abdominal aorta of the recipient. The transplanted heart was unloaded after transplantation, and only the coronary venous blood entered the left ventricle (LV) through the coronary sinus, the right atrium, the right ventricle, the pulmonary artery (PA), the lungs, the pulmonary veins, and the left atrium (Figure 1,A). Two weeks later, the transplanted heart was reloaded by anastomosing the right PA to the distal abdominal aorta. Saturated blood entered the LV of the donor heart through the right lung, the pulmonary vein, and the left atrium (Figure 1, B). The heart pumped out the blood, which accumulated in the LV from both the coronary sinus and the PA into the abdominal aorta. An outline of the experimental protocol is provided in Figure 2.

\section{Heterotopic Heart-Lung Transplantation}

The donor rats were anesthetized by means of an intraperitoneal injection of ketamine $(50 \mathrm{mg} / \mathrm{kg}$ of body weight) and pentobarbital sodium $(50 \mathrm{mg} / \mathrm{kg}$ of body weight). The animals were intubated and ventilated with a Harvard ventilator (respiration rate, 60 breaths/min; tidal volume, $3 \mathrm{~mL}$ ). The heart and lungs were exposed through a median sternotomy. Both the right and left superior venae cavae and the inferior vena cava (IVC) were taped. The mediastinal lobe of the right lung was resected. The left diaphragm was incised posteriorly near the aorta to provide a long segment of the thoracoabdominal aorta, and 2 sections were isolated with tapes.

Before the heart and lungs were harvested, the recipient rat was anesthetized with the inhalation of isoflurane (1.5\%) and ventilated as described above. After the abdomen was opened through a midline incision, the intestines were pushed to the right side and were kept moist during the operation.

After an injection of $300 \mathrm{U}$ of heparin sodium into the donor's IVC, the distal thoracoabdominal aorta was ligated, a 20-gauge needle was inserted upward into the thoracic aorta, and $20 \mathrm{~mL}$ of cardioplegia (cold saline with $20 \mathrm{mEq} / \mathrm{L}$ of potassium chloride) was injected into the heart through the thoracic aorta. The IVC and both the right and left superior venae cavae were ligated and divided. Then the ascending aorta and the trachea were transected, 


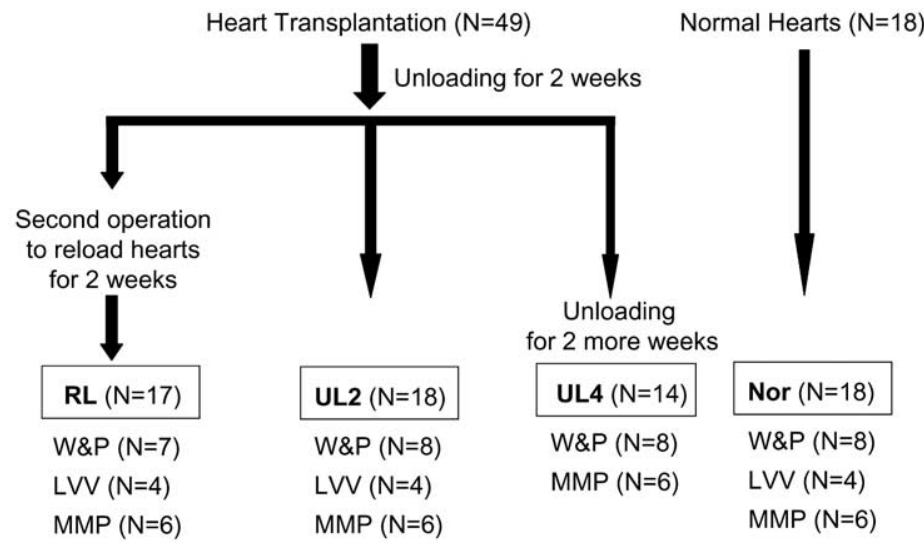

Figure 2. In this study 49 heart and lung transplantations were performed in total. The second operation was performed on 17 transplanted hearts (RL). Eighteen transplanted hearts were removed 2 weeks after transplantation (UL2). Fourteen transplanted hearts were kept unloaded for a total of 4 weeks (UL4). Eighteen normal hearts (Nor) were also evaluated. Six hearts from each group were used for MMP analysis, and these hearts were not used for left ventricular pressure and volume analysis. W\&P, Weight and pressure; $L V V$, left ventricular volume.

and the heart and lungs were excised and transferred into a container containing a cold cardioplegic solution until transplantation.

The recipient's abdominal aorta was clamped, and a 3-mm longitudinal incision was made in the aorta to which the donor's ascending aorta was anastomosed with 7-0 polypropylene sutures. The donor heart $(n=49)$ was kept cold with wet gauze during the anastomosis. Before the suture was tied, air was removed from the donor's heart and ascending aorta, and the clamps were released. After the heart started beating, the right PA was dissected and wrapped in preparation for the second operation. Sepra film (Genzyme, Tokyo, Japan) was placed around the anastomosis to reduce adhesions. The abdomen was closed with 3-0 absorbable sutures.

\section{Reloading the LV of the Donor Heart (Second Operation)}

Two weeks after heart-lung transplantation, the rat was anesthetized with inhalation of isoflurane, as described above, and the abdomen was opened. The abdominal aorta just distal to the previous anastomosis was dissected. The wrapped right PA of the donor was exposed and ligated proximally. The distal PA was clamped, and the right PA was divided just distal to the ligature. The abdominal aorta was clamped, and a 2-mm incision was created. The distal end of the right PA was anastomosed to the incision in the abdominal aorta with a continuous 8-0 suture. The clamps were released after the anastomosis was completed. The right lung turned red as soon as the clamps were released. The abdomen was closed with continuous 3-0 absorbable sutures.

\section{Measurement of Donor's Left Ventricular Pressure, Recipient's Aortic Pressure, Left Ventricular Weight, and Left Ventricular Volume}

The donor's left ventricular pressure, the recipient's aortic pressure, the left ventricular weight, and the left ventricular volume were measured at 4 different times after the operation (Figure 2). Twelve hearts were evaluated 2 weeks after unloading (UL2), and
8 hearts remained in the unloaded state and were evaluated 4 weeks after transplantation (UL4). Two weeks after transplantation, 17 hearts underwent reoperation, and the LV was reloaded, and 2 weeks later ( 4 weeks after transplantation), the reloaded hearts were evaluated (RL, $\mathrm{n}=7$ ). Left ventricular weights and volumes of 12 normal hearts were also evaluated. Six hearts from each group were used for matrix metalloproteinase (MMP) analysis, which were not used for left ventricular pressure and volume analysis.

After achievement of general anesthesia, the transplanted heart was exposed. A 22-gauge angiocath was inserted into the LV through the apex, and the catheter was connected to a pressure transducer (model p10EZ; Viggo-Spectramed, Oxnard, Calif) and a differentiator amplifier (model 11-G4113-01; Gould Instrument System Inc, Valley View, Ohio). The pressures were recorded with a computer. The left ventricular end-diastolic pressure (LVEDP) and the heart rate for 5 seconds were recorded and averaged with the computer software Ponemah Physiology program (Gould Instrument Systems, Inc). After the left ventricular pressure was recorded, the tip of the catheter was moved into the aorta, and the aortic pressure was recorded ( $\mathrm{n}=8$ /group).

After measuring the pressures, the hearts were removed and immediately put into cold saline. The right ventricles were removed carefully, and the left ventricular weight was measured ( $n=6-8$ in each group). For morphologic studies, the transplanted hearts were arrested with $10 \mathrm{~mL}$ of cardioplegic solution and fixed with formalin at a pressure of $30 \mathrm{~mm} \mathrm{Hg}(\mathrm{n}=4$ in each group). The LV was cut into 2-mm-thick slices, and the left ventricular volume was calculated by means of planimetry.

\section{Quantification of MMP-9}

Six hearts in each group were also quickly excised and arrested in ice-cold phosphate-buffered saline. The anterior free walls of the hearts were snap-frozen in liquid nitrogen and stored at $-80^{\circ} \mathrm{C}$ for enzyme activity. The relative abundance of MMP-9 in left ven- 
(A) UL2

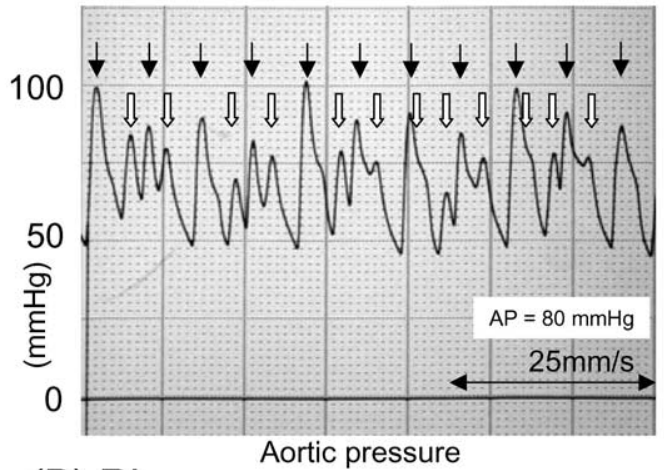

(B) RL

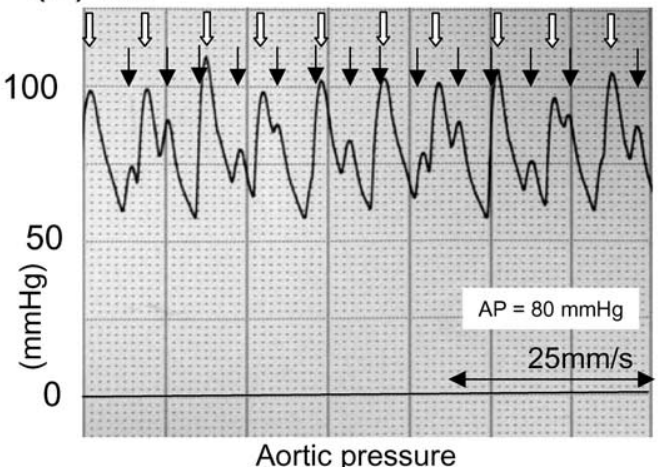

$\left(A^{\prime}\right)$

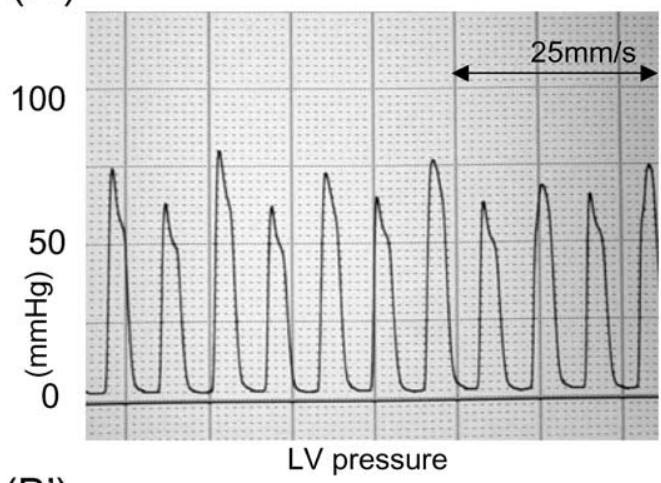

(B')

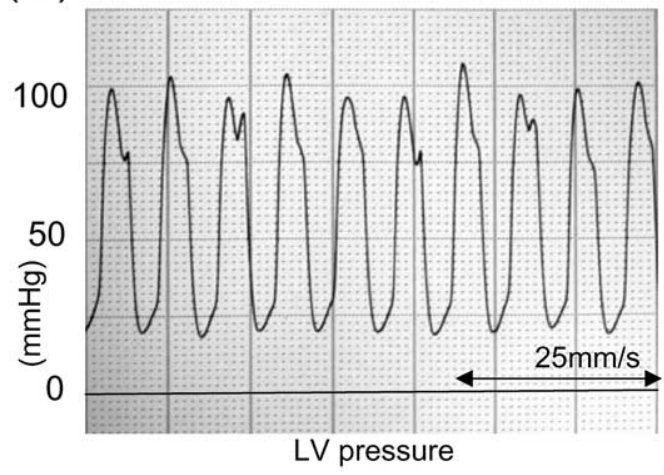

Figure 3. The pressure traces of the donor $L V$ and the recipient aorta. The left ventricular pressure in the unloaded heart $(A)$ is lower than the recipients' aortic pressure $\left(A^{\prime}\right)$ but higher in the reloaded heart ( $B$ and $\left.B^{\prime}\right)$. When the aortic pressure is changed by the level of anesthesia, this tendency remains consistent. In the unloaded heart, the left ventricular pressure is always lower than the recipient's aortic pressure ( $C$ and $C^{\prime}$ ), and in the reloaded heart the left ventricular pressure is always higher than the aortic pressure ( $D$ and $\left.D^{\prime}\right)$. When the right pulmonary artery is clamped, the LVEDP slowly decreases. When the PA is then unclamped, both LVEDP and the left ventricular systolic pressure slowly increase. $A P$, Aortic pressure; $L V$, left ventricle; black arrows, the aortic pressure; white arrows, the left ventricular pressure; rt, right.

tricular myocardial extracts was examined with standard immunoblotting procedures, as described previously. ${ }^{25}$

\section{Data Analysis}

All results were presented as means $\pm \mathrm{SD}$. Comparisons between groups were performed by means of analysis of variance, and when the $\mathrm{F}$ ratio was statistically significant, differences were specified by using the Tukey multiple range test.

\section{Results}

Forty-nine heart-lung transplantations were performed in total. The average time for heart-lung transplantation was $73.6 \pm 6.1$ minutes. The operative time for the recipients was $53.7 \pm 5.2$ minutes. The ischemic time (from injection of cardioplegia to declamping) was $22.7 \pm 1.7$ minutes, the clamp time was $17.6 \pm 1.6$ minutes, and the time for the anastomosis was $13.4 \pm 1.3$ minutes. All hearts started beating immediately after declamping. After several practice procedures, all rats survived heart-lung transplantation.
Seventeen animals underwent operations at 2 weeks after heart-lung transplantation for reloading. The average operating time for the second operation was $77.4 \pm 7.4$ minutes. Adhesions were found around the right PA and the abdominal aorta, despite the use of Sepra film. The clamp time for the second operation was relatively long $(24.3 \pm 2.4$ minutes), but there was no ischemic time to the transplanted hearts because the aorta was clamped distal to the previous anastomosis. After declamping, the right lung became perfused with arterial blood, and the color immediately turned red. Two weeks after the second operation, the right lung was still bright red in all animals.

Figure 3 shows representative examples of the pressure traces in the unloaded and loaded ventricles. The left ventricular systolic pressures $(90 \pm 7 \mathrm{~mm} \mathrm{Hg}$ ) were consistently lower than the recipients' aortic pressure $(98 \pm 6 \mathrm{~mm}$ $\mathrm{Hg}$ ) in the unloaded state. After reloading the ventricle, the systolic ventricular pressures $(91 \pm 7 \mathrm{~mm} \mathrm{Hg}$ ) were inter- 
(C) UL2

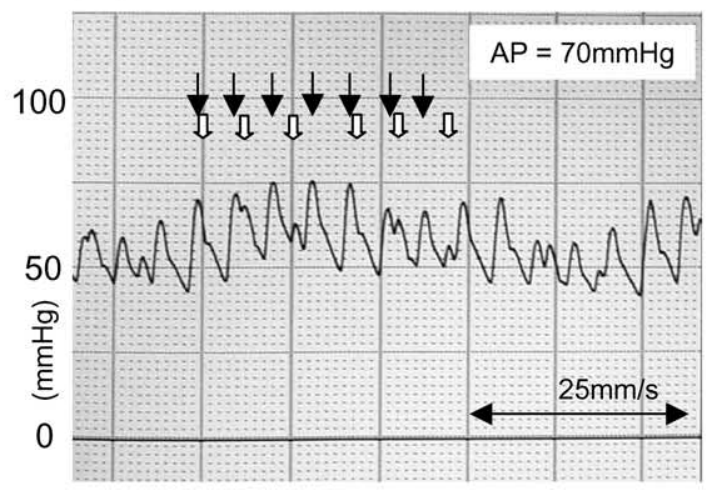

(D) $\mathrm{RL}$

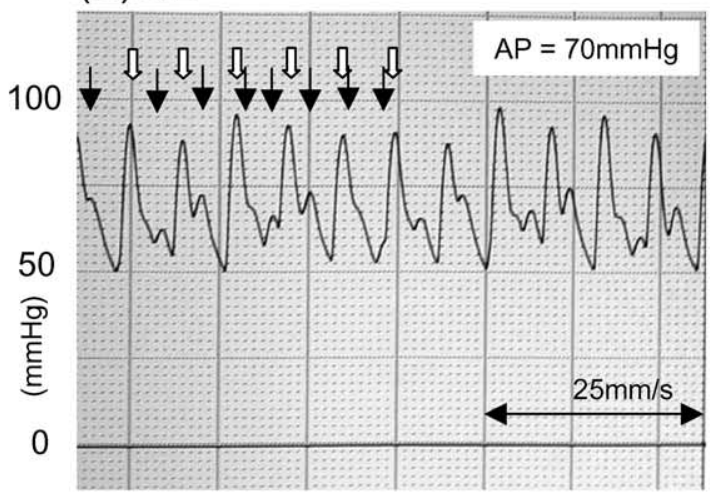

(C')

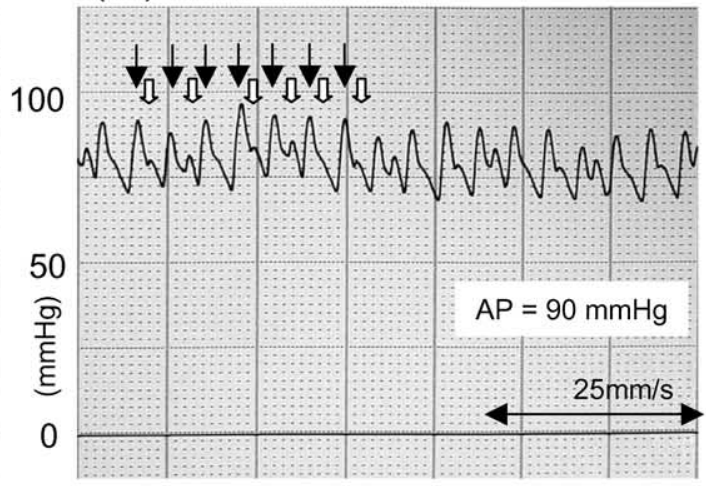

(D')

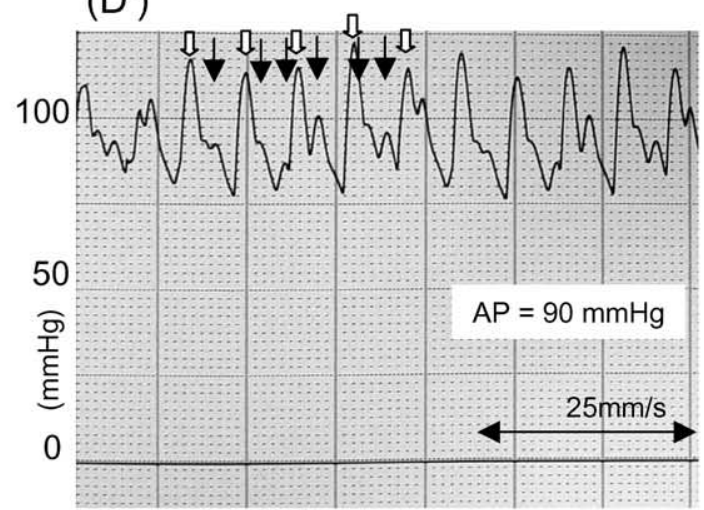

(E) Declamping of rt. PA

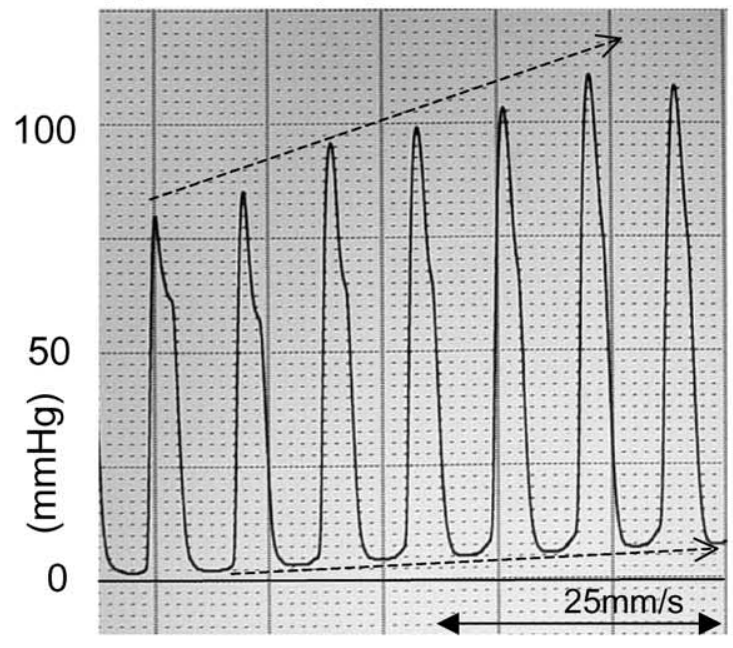

Figure 3. Continued.

mittently greater than the recipient aortic pressure $(89 \pm 8$ $\mathrm{mm} \mathrm{Hg}$ ), resulting in intermittent ventricular ejection.

The LVEDP of the hearts before transplantation into the abdomen varied between 2 and $8 \mathrm{~mm} \mathrm{Hg}$, depending on the anesthetic level, the extent of the bleeding from the sternotomy, and whether the pleura was opened. After 2 weeks in the unloaded state (UL2), LVEDP was $4.3 \pm 1.1 \mathrm{~mm} \mathrm{Hg}$ (Figure 4). After an additional 2 weeks in the unloaded state 


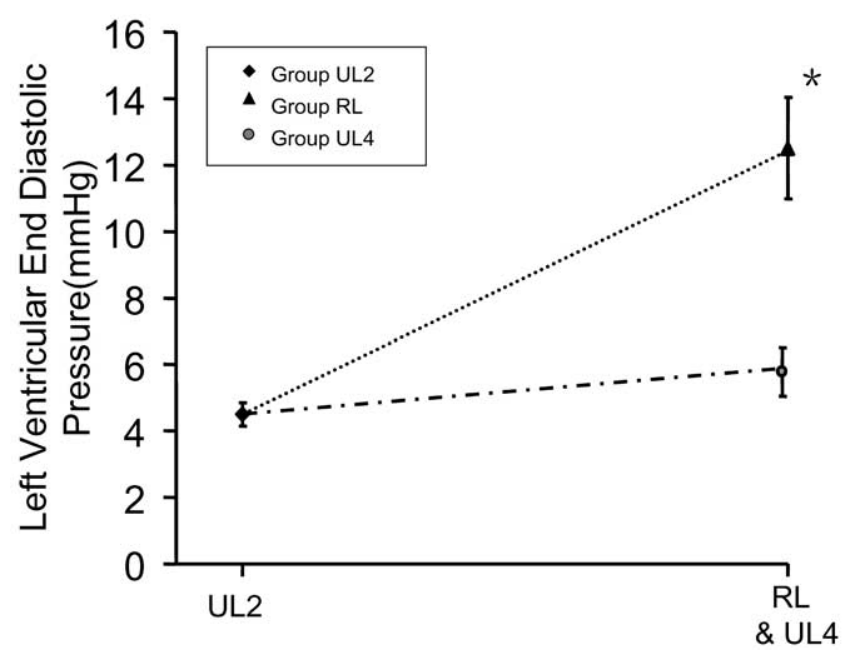

Figure 4. LVEDP. After the second operation (RL), the LVEDP increased significantly compared with the LVEDP of the unloaded hearts 2 weeks (UL2) and 4 weeks (UL4) after heart-lung transplantation. ${ }^{*} \boldsymbol{P}<.05$ compared with UL2.

(UL4), LVEDP was $5.3 \pm 0.6 \mathrm{~mm} \mathrm{Hg}$, which was not different from the LVEDP at 2 weeks (UL2). After the hearts were reloaded (RL) for 2 weeks, the LVEDP was $12.4 \pm 3.7 \mathrm{~mm} \mathrm{Hg}$, which was significantly higher than the LVEDP in the unloaded state at 2 weeks (UL2, $P<.01$ ) or 4 weeks (UL4, $P<.01$ ). Heart rates in groups UL2, UL4, and RL were $253 \pm 39,263 \pm 29$, and $252 \pm 39$ beats/min, respectively. There were no statistical differences among the 3 groups.

Figure 5, A, depicts the transplanted hearts during the experiment. Normal left ventricular weight was $561 \pm 31$ $\mathrm{mg}$ (Figure 5, B). At 2 weeks in the unloaded state (UL2), the left ventricular weight decreased to $312 \pm 22 \mathrm{mg}(P<$ $.01)$. When the hearts remained unloaded for 2 more weeks (UL4), the low weight was maintained (301 $\pm 22 \mathrm{mg}, P=$ .32). When the hearts were reloaded for 2 weeks (RL), the left ventricular weight increased $(562 \pm 67 \mathrm{mg})$, which was significantly greater than that of UL2 and UL4 $(P<.01$ and $P<.01$, respectively) and not different from that of the normal LV $(P=.41)$.

The left ventricular volume of the normal heart was 0.32 $\pm 0.02 \mathrm{~mL}$ (Figure 5,C). After 2 weeks of unloading (UL2), the left ventricular volume decreased significantly to $0.16 \pm 0.01 \mathrm{~mL}(P<.001)$. After 2 weeks of reloading (RL), the left ventricular volume enlarged again to $0.28 \pm$ $0.05 \mathrm{~mL}(P=.004$ compared with group $\mathrm{U} 2)$, which was as similar to that seen in normal hearts $(P=.20)$.

MMP-9 levels in the myocardium decreased after 2 weeks of unloading (UL2, $P=.05$ ) and remained low when the hearts were kept unloaded longer (UL4, $P=.01$ ) compared with that seen in the normal hearts (Figure 6).
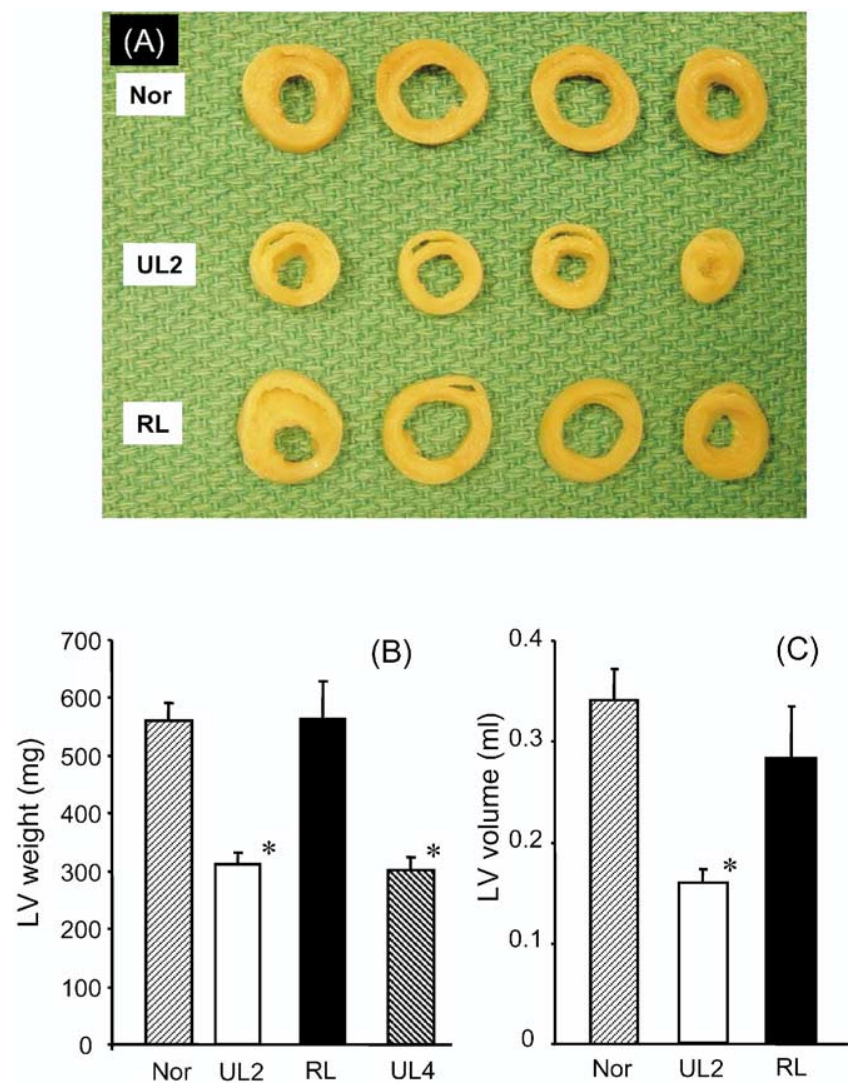

Figure 5. A, Photographs of the normal heart (Nor), the unloaded heart (UL2), and the reloaded heart (RL). After unloading, the heart becomes smaller than the normal heart. After reloading, the heart dilates. B, The weight of the LVs decreased significantly 2 weeks after the heart-lung transplantation (UL2) but increased 2 weeks after reloading (RL). C, The left ventricular volume significantly decreased compared with that of the normal heart after unloading (UL2), but 2 weeks after reloading (RL), the left ventricular volume increased again. ${ }^{*} P<.05$ compared with the left ventricular volume of the normal heart.

However, the MMP-9 level increased $(P=.025)$ when the unloaded hearts were reloaded compared with that in the UL4 group.

\section{Discussion}

LVADs have been used extensively as a bridge to transplantation, and they have been proposed for use as destination therapy. Eventually, the devices might be used as a bridge to recovery. However, the initial experience with this process has been disappointing. A variety of interventions, such as cell transplantation, have been proposed to treat the unloaded heart receiving LVAD assistance to prevent recurrent failure after LVAD removal. None of these interventions have been adequately tested because an animal model of left ventricular unloading followed by left ven- 
tricular reloading has not been described. Therefore, we developed this surgical model, which will permit the testing of alternate strategies to prevent recurrent cardiac failure after reloading.

This new heterotopic heart transplantation model adequately unloaded and then reloaded the heart. We evaluated the hearts after 2 weeks in the unloaded condition and again after 2 weeks in the reloaded state. However, the time course could be altered as long as the physiologic conditions of the implanted organs are maintained. A longer duration in the unloaded state might be required for normalization of ischemically injured hearts. A longer duration after reloading might also be required to determine the fate of interventions, such as cell transplantation.

The small ventricular volumes and low weights after unloading for 2 weeks demonstrated the adequacy of ventricular unloading. ${ }^{26}$ After the first operation, only the coronary blood flow entered the LV, and this blood was eventually ejected, despite the low left ventricular systolic pressure. After the second operation, a large volume of saturated blood continuously entered the LV from the abdominal aorta (in addition to the coronary venous blood) and was ejected into the abdominal aorta. After transplantation, the hearts were unloaded with low pressures and volumes. After the second operation, the heart was reloaded, and both pressures and volumes returned to the pretransplantation values. Therefore, this model simulates the conditions present when cardiomyopathic hearts are unloaded by means of LVAD support and reloaded by means of LVAD removal.

At the first operation, the single anastomosis reduced the ischemic time compared with the time required for conventional heterotopic rat heart transplantation. The short ischemic time and short clamp time might have contributed to the low mortality and morbidity we experienced. A limitation of the present study is that we did not include decompensated hearts, such as drug-induced or ischemic cardiomyopathic rat hearts. The short ischemic time required for heart transplantation might permit the implantation of decompensated hearts, which will determine the clinical relevance of this model. The second operation was accomplished without ischemic heart damage, but adhesions provided a technical challenge. The bioabsorbable sheet might have reduced but did not prevent adhesion formation, especially around the PA and trachea. To facilitate the second operation, we wrapped the right PA to protect it from even more dense adhesion formation. The wrap helped to identify and dissect the right PA at the second operation. The volume of the blood, which flowed into the transplanted heart from the abdominal aorta after the second operation, was not estimated in our experiment. The anastomosis between the PA and the abdominal aorta was $2 \mathrm{~mm}$ in diameter and larger than the diameter of the abdominal aorta.

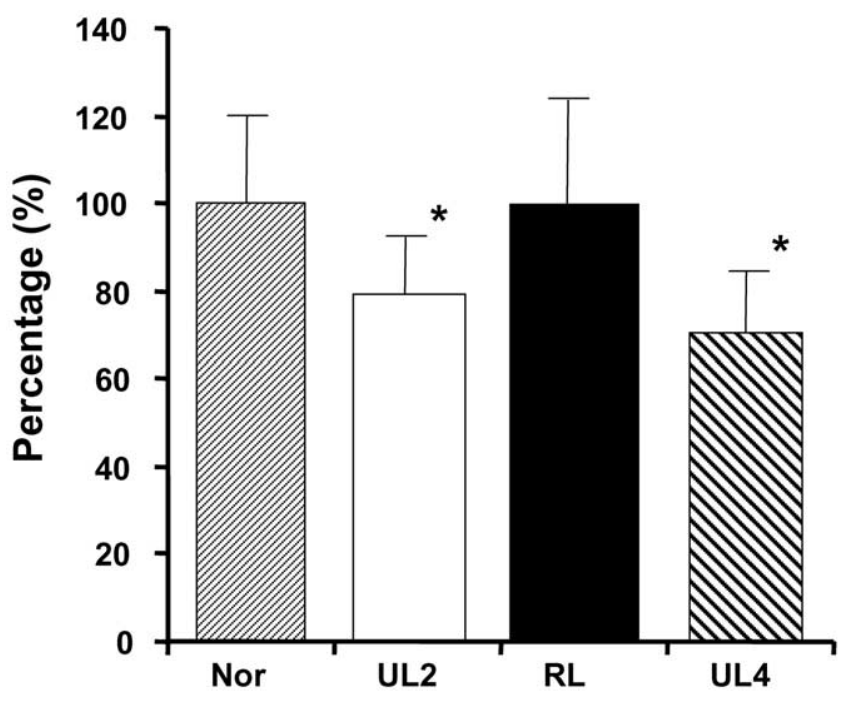

Figure 6. The changes in MMP-9 levels are depicted during the study. Two weeks after the heart transplantation (2 weeks of unloading), MMP-9 levels significantly decreased compared with those of the normal hearts and stayed low, whereas the hearts were kept unloaded for the additional 2 weeks. After the hearts were reloaded, MMP-9 levels increased again. ${ }^{*} P<.05 \mathrm{com}-$ pared with the normal hearts. Nor, The group of normal hearts; $U L 2$, the hearts after 2 weeks of unloading; $R L$, the hearts reloaded for 2 weeks after 2-week unloading; UL4, the hearts unloaded for 4 weeks.

Therefore the blood flow into the transplanted heart was only limited by the pulmonary vascular resistance.

We found that both the size and weight of the implanted hearts decreased after unloading and enlarged again after reloading. The changes in size and weight were probably the result of unloading and reloading. The changes were unlikely to have been caused by myocardial ischemia because the ischemic time was shorter than those reported previously. ${ }^{20-24} \mathrm{~A}$ similar response was described in patients after LVAD therapy, with left ventricular dilation and cardiac failure often recurring after LVAD removal. The functional recovery was frequently only temporary. The injured myocardium did not maintain its architecture but dilates, and heart failure recurs after the removal of LVAD support. Because the normal heart was used in this study, the regression of ventricular weight was not necessarily beneficial. Future research is required to study the effect of ventricular unloading on hearts with a dilated cardiomyopathy. This model will help us to understand the process of reestablishing normal function in cardiomyopathic hearts, to understand the mechanisms of reverse remodeling during LVAD therapy, and to determine whether new therapies, such as cell transplantation, can prevent recurrent dilation and cardiac failure after LVAD removal. 
We evaluated the change in MMP-9 levels in the hearts before and after unloading and reloading. We found that unloading decreased MMP-9 levels, which remained low as long as the hearts were unloaded. The same phenomena has been reported after LVAD support in patients with cardiomyopathic hearts. ${ }^{7}$ Other groups described changes in gene expression and calcium flux after cardiac unloading, ${ }^{27-29}$ but no information has been reported on gene expression or molecular alterations after LVAD removal. In this surgical model, MMP-9 levels increased to normal values when the hearts were reloaded. The increased MMP levels might contribute to the recurrence of heart failure after LVAD removal.

In conclusion, this new heterotopic rat heart transplantation model can provide both a nonworking heart model and a working heart model after a variable period of unloading. Therefore the model will simulate the conditions of LVAD support for the failing heart and cardiac recovery after removal of an LVAD.

We thank Professor Tohru Sakamoto, Department of Thoracic Organ Replacement, Graduate School of Medicine, Tokyo Medical and Dental University, for technical advice.

\section{References}

1. De Rose JJ Jr, Umana JP, Argenziano M, Catanese KA, Gardocki MT, Flannery M, et al. Implantable left ventricular assist devices provide an excellent outpatient bridge to transplantation and recovery. J Am Coll Cardiol. 1997;30:1773-7.

2. Bank AJ, Mir SH, Nguyen DQ, Bolman RM III, Shumway SJ, Miller LW, et al. Effects of left ventricular assist devices on outcomes in patients undergoing heart transplantation. Ann Thorac Surg. 2000;69: 1369-75.

3. Milting H, Banayosy AE, Kassner A, Fey O, Sarnowski P, Arusoglu L, et al. The time course of natriuretic hormones as plasma markers of myocardial recovery in heart transplant candidates during ventricular assist device support reveals differences among device types. $J$ Heart Lung Transplant. 2001;20:949-55.

4. Ogletree-Hughes ML, Stull LB, Sweet WE, Smedira NG, McCarthy $\mathrm{PM}$, Moravec CS. Mechanical unloading restores $\beta$-adrenergic responsiveness and reverses receptor downregulation in the failing human heart. Circulation. 2001;104:881-6.

5. Bruckner BA, Stetson SJ, Perez-Verdia A, Youker KA, Radovancevic $\mathrm{B}$, Connelly JH, et al. Regression of fibrosis and hypertrophy in failing myocardium following mechanical circulatory support. J Heart Lung Transplant. 2001;20:457-64.

6. Zafeiridis A, Jeevanandam V, Houser SR, Marglies KB. Regression of cellular hypertrophy after left ventricular assist device support. Circulation. 1998;98:652-62.

7. Li YY, Feng Y, McTiernan CF, Pei W, Moravec CS, Wang P, et al. Downregulation of matrix metalloproteinases and reduction in collagen damage in the failing human heart after support with left ventricular assist devices. Circulation. 2001;104:1147-52.

8. Heerdt PM, Holmes JW, Cai B, Barbone A, Madigan JD, Reiken S, et al. Chronic unloading by left ventricular assist device reverses contractile dysfunction and alters gene expression in end-stage heart failure. Circulation. 2000;102:2713-9.
9. Francis GS, Anwar F, Bank AJ, Kubo SH, Jessurun J. Apotosis, Bcl-2, and proliferating cell nuclear antigen in the failing human heart: observations made after implantation of left ventricular assist device. J Card Fail. 1999;5:308-15.

10. Kumpati GS, McCarthy PM, Hoercher KJ. Left ventricular assist device as a bridge to recovery: present status. J Card Surg. 2001;16: 294-301.

11. Entwistle JW 3rd. Long-term mechanical ventricular assistance toward myocardial recovery. Cardiol Clin. 2003;21:75-82.

12. Hetzer R, Müller JH, Weng YG, Loebe M, Wallukat G. Midterm follow-up of patients who underwent removal of a left ventricular assist device after cardiac recovery from end-stage dilated cardiomyopathy. J Thorac Cardiovasc Surg. 2000;120:843-55.

13. Mancini DM, Beniaminovitz A, Levin H, Catanese K, Flannery M, DiTullio M, et al. Low incidence of myocardial recovery after left ventricular assist device implantation in patients with chronic heart failure. Circulation. 1998;98:2383-9.

14. Helman DN, Maybaum SW, Morales DLS, Williams MR, Beniaminovitz A, Edwards NM, et al. Recurrent remodeling after ventricular assistance: is long-term myocardial recovery attainable? Ann Thorac Surg. 2000;70:1255-8.

15. Gorcsan J III, Severyn D, Murali S, Kormos RL. Non-invasive assessment of myocardial recovery on chronic left ventricular assist device: results associated with successful device removal. J Heart Lung Transplant. 2003;22:1304-13.

16. Ghostine S, Carrion C, Souza LCG, Richard P, Bruneval P, Vilquin JT, et al. Long-term efficacy of myoblast transplantation on regional structure and function after myocardial infarction. Circulation. 2002; 106:I131-6.

17. Tomita S, Li RK, Weisel RD, Mickle DAG, Kim EJ, Sakai T, et al. Autologous transplantation of bone marrow cells improves damaged heart function. Circulation. 1999;100:II247-56.

18. Abbott CP, Lindsey ES, Creach O Jr, DeWitt CW. A technique for heart transplantation in the rat. Arch Surg. 1964;98:645-52.

19. Ono K, Lindsey ES. Improved technique of heart transplantation in rats. J Thorac Cardiovasc Surg. 1969;57:225-9.

20. Yokoyama H, Ohmi M, Murata S, Nakame T, Tabayashi K, Mohri H. Proposal of a working left heart model with a heterotopic transplantation technique in rats. J Heart Lung Transplant. 1995;14:706-12.

21. Korecky B, Masika M. Direct effect of increased hemodynamic load on cardiac mass. Circ Res. 1991;68:1174-8.

22. Klein I, Hong C, Schreiber SS. Isovolumic loading prevents atrophy of the heterotopically transplanted rat heart. Circ Res. 1991;69:1421-5.

23. Maruyama T, Swartz MT, McBride LR, Pennington DG. Working heart model of heterotopic heart-lung transplantation in rats. J Thorac Cardiovasc Surg. 1994;107:210-5.

24. Yoshida S, Dodd SJ, del Nido PJ, Williams DS, Ho C. Cardiac function of transplanted rat hearts using a working heart model assessed by magnetic resonance imaging. $J$ Heart Lung Transplant. 1999;18:1054-64.

25. Fedak PWM, Altamentova SM, Weisel RD, Nili N, Ohno N, Verma S, et al. Matrix remodeling in experimental and human heart failure: a possible regulatory role for TIMP-3. Am J Physiol Heart Circ Physiol. 2003;284:H626-34.

26. Klein I, Hong C, Schreiber SS. Cardiac atrophy in the heterotopically transplanted rat heart: in vitro protein synthesis. J Mol Cell Cardiol. 1990;22:461-8.

27. Depre C, Shipley GL, Chen W, Han Q, Doenst T, Moore ML, et al. Unloaded heart in vivo replicates fetal gene expression of cardiac hypertrophy. Nat Med. 1998;4:1269-75.

28. Klein I, Ojamaa K, Samarel AM, Welikson R, Hong C. Hemodynamic regulation of myosin heavy chain gene expression. Studies in the transplanted rat heart. J Clin Invest. 1992;89:68-73.

29. Kolar F, MacNaughton C, Papousek F, Korecky B, Rakusan K. Changes in calcium handling in atrophic heterotopically isotransplanted rat hearts. Basic Res Cardiol. 1995;90:475-81. 